ББК 63.5

DOI 10.31554/2222-9175-2019-35-10-96-101

М. М. Содномпилова

ГИАРОГРАФИЧЕСКИЕ ОБЪЕКТЫ

«СОКРОВЕННОГО СКАЗАНИЯ МОНГО $О В$ » (MONGYOL-UN NIYUCCA TOBČIYAN) B KOHTEKCTE ИСТОРИЧЕСКОЙ ГЕОГРАФИИ ВНУТРЕННЕЙ АЗИИ

В исследованиях исторической географии особый интерес представляют гидрографические объекты. Гидрографическая терминология представляет собой весьма древний и устойчивый слой лексики, в образовании которой доминируют изобразительные слова. Выявлено, что названия самых крупных рек региона идентифицируются с существующими в настоящее время гидрографическими объектами. Названия небольших водных источников, таких как названия ручьев, не сохранились, и локализация их на современной карте затруднена. Отмечается преобладание в ССМ гидронимов мүрэн, горхон над булаг, усун и отсутствие гидронима гол.

Ключевые слова: гидронимы, средневековье, ХІІ в., монголы, мурэн, нуур, горхон, булаг, усун.

M. M. Sodnompilova

\title{
HYDROGRAPHIC OBJECTS OF THE SECRET HISTORY OF THE MONGOLS (MONGYOL-UN NIYUCA TOBCIYAN) IN THE CONTEXT OF THE HISTORICAL GEOGRAPHY OF INNER ASIA
}

In studies of historical geography, hydrographic objects are of particular interest. Hydrographic terminology is a very ancient and stable layer of vocabulary, in the formation of which image words dominate. It is revealed that the names of the largest rivers of the region are identified with the existing hydrographic objects. The names of small water sources such as streams have not been preserved and their localization on the modern map is difficult. There is a predominance of such hydronyms in the SHM as müren, qoroqan, bulaq, usun, and the absence of a hydronym as $\gamma o l$.

Keywords: hydronyms, Middle Ages, $12^{\text {th }}$ century, Mongols, müren, nau/nuur, qoroqan/ rorqon, bulaq/bular, usun.

$\mathrm{M}$ онгольские народы расселились на огромной территории Внутренней Азии, включающей природные зоны от пустыни до тундры, от высокогорья до степных равнин. Освоение кочевниками этого разнородного пространства одна из насущных проблем истории кочевых обществ, не потерявшая своей актуальности. Один из исторических этапов освоения монголами данного региона отражен в известном средневековом памятнике «Сокровенное сказание монголов». На мате-

СОДНОМПИЛОВА Марина Михайловна - доктор исторических наук, ведущий научный сотрудник отдела истории, этнологии и социологии Федерального государственного бюджетного учреждения науки «Институт монголоведения, буддологии и тибетологии СО РАН» (Улан-Удэ, Россия). E-mail: sodnompilova@yandex.ru. 
риалах источника, отражающего события XII в., мы можем проследить ключевые топонимические термины, отражающие видение монголами окружающей природы, обозначить места, где происходили важные события в жизни основных персонажей сказания - Темучжина и его предков и попытаться сопоставить их с современной картой данного исторического региона.

Наибольший массив терминов, отражающих природное окружение монголов и ключевые локусы исконной монгольской земли, маркированные событиями, сопутствовавшими становлению Чингис-хана, концентрируется в первой половине повествования. Особый интерес представляют гидрографические объекты. Актуальность исследования обоснована тем, что данная терминология представляет собой весьма древний и устойчивый слой лексики, изучение которой позволит раскрыть не только богатство и выразительные возможности древнемонгольского языка, но и взаимоотношение этноса с миром в древний период. Е. В. Сундуева подчеркивает доминирующую роль изобразительных слов в образовании гидрографической терминологии в монгольских языках и считает, что именно зрительно-слуховое восприятие послужило основой номинации этих реалий [2010: 42, 46]. В своем исследовании мы опираемся на тексты «Сокровенного сказания монголов», переведенного С. М. Козиным, и более позднюю, с новыми данными и обширными комментариями, работу И. де Рахевильца [The Secret History of the mongols 2004], обращясь также к аналитическим работам П. Пеллиота [Pelliot 1949], А. В. Дыбо и др.

Пространство, заселенное монгольскими кочевниками, изобилует реками, озерами, родниками. Эти природные объекты наряду с горами становились главным ключевым маркером территории проживания средневековых монголов и опорной точкой, от которой расходились траектории новых путей в освоении пространства. Об исключительной значимости водного источника для кочевника свидетельствует вопрос, с которым обращались к чужеземцу: «где находится земля, где ты “упал" (родился), вода, которую ты пил?» Река, как и земля, упоминается в качестве связующего определенные монгольские сообщества элемента в различных источниках, повествующих о монголах. «Племя куралас обратило в бегство Боту из племени икиpac. Уходя разгромленным от них, он присоединился к Чингиз-хану в этом месте... Они там вместе жили и пили воду [реки] Балджиунэ» [Рашид-ад-дин 1952: 131].

В тесте «Сокровенного сказания» представлены все виды водных источников, отраженные в следующих терминах:

1. мүрэн/müren. В монгольских языках термином мүрэн/müren/mören (широкая река) обозначаются крупные водные источники [Сравнительно-историческая грамматика... 2006: 379]. Относительно генезиса термина на данный момент все еще не сложилось единого мнения. Г. Рамстедт склонен связывать этот термин с тунгусоманьчжурскими языками, сопоставляя muren с т.-ма. му 'вода': эвенк., нег., ороч. мy, ульч. му/муэ, чж. тиһ 'вода', уд. мудэ [2010: 42]. Привлечение нового материала и новые исследования, выполненные М. Рясянен, дают основания Э. Р. Тенишеву, А. В. Дыбо и другим тюркологам ставить вопрос об исконном характере тюркского названия реки мӧрен/бӧрен [Сравнительно-историческая грамматика... 2006: 380]. Е. В. Сундуева полагает, что лексема восходит к древнему изобразительному корню $\mathrm{mur} / \mathrm{mör}$ 'нечто искривленное, изогнутое, извивающееся' [Сундуева 2010: 42]. В «Сокровенном сказании» muren - один из ключевых гидрографических терминов. Самой первой крупной рекой под этим термином, отмечаемым в ССМ, выступает р. Ононмурэн, на берегах которой поселились предки Чингис-хана, переплыв море Тенгис. Онон-мурэн фиксируется в ситуации отделения Бодончара от своих братьев. Он поселился на берегу реки (п-ве или о-ве Бальжун-арал (Baljun-aral)) и построил себе шалаш из травы. 
В § 53, в эпизоде захвата в плен Амбагай хана фиксируется крупная река Uršiunmuren/Уршун мүрэн, которая присутствует и на современных картах под названием Оршон-гол. Согласно ССМ, местность, куда направлялся Амбагай-хан, находилась на берегах реки Uršiun-müren/Уршун мүрэн между двумя озерами - Buyür-naur (Буир-нур) и Kölen-naur (ныне Далай-нор и Буир-нор в Хулун-Буирском аймаке KHP).

К крупным рекам в средневековье относилась и р. Тола. О Tuula-müren говорится в $§ 104-$ на ее берегах находилась ставка Ван-хана. Многократно упоминается в ССМ крупная река Керулен (Keluren-müren), с которой были связаны многие важные события в жизни Темучжина. В ССМ верховья р. Керулен также соотносятся с ареалом Burqi-erki, выделенным И. де Рахевильцем.

Три крупных реки, идентифицируемых на современной карте региона, упоминаются в цикле сражений Темучжина, Джамухи и Ван-хана с меркитами, отраженных в $\S 104,105,106,110$. Это реки Селенга и Орхон, на месте слияния которых на о-ве Талхун (Talqun aral) расположился один из меркитских вождей Дайр-усун. Реку Qilqo-müren, идентифицированную С. М. Козиным как Хилок, собирается пересечь Джамуха, ставя задачу настигнуть в степи Харачжи ХаатайДармалу.

В местности, где впадает в р. Эргунэ (Ergüne-müren) р. Кан (Xan-müren), на вершине поросшей лесом горы произошло возведение в Гур-ханы Чжамухи (§ 142). Другая известная сегодня река - Халха упоминается в $§ 175$. Места, по которым протекает Халха, и место ее впадения в Буир-нур маркированы военной кампанией Чингисхана с Ван-ханом. Общепризнанным считается сопоставление средневекового названия Эргунэ с известным в настоящее время гидрографическим объектом - р. Аргунь.

2. горхон/qoroqan. Наиболее часто в описаниях местности, где проходят юные годы Темучжина, упоминаются небольшие ручьи, стекающие со склонов горного массива Бурхан-халдун. Несколько раз отмечается ручей qoroqan Tenggelik. Согласно исследованиям П. Пелльо и поддержавшего его И. де Рахевильца, такая форма написания водного источника является результатом более поздней транскрипции, предшествовала которой форма Tünggelik [Pelliot 1949: 5; The Secret History... 2004: 402]. Впервые этот гидрографический объект фиксируется в описании встречи Добун-Мергена с семьей Алан-гоа, которую он увидел с вершины Бурхан-халдуна, в $\S 5$. Этот же ручей упоминается в сюжете бегства семьи Темужчина от внезапно напавших меркитов в $\S 100$. Няня Хоачин, посадив в возок Борте-учжин, спешит вверх по ручью Tünggelik. Этимология названия водного источника, по мнению М. Д. Эвэн и Р. Поп, связана с образом извивающейся змеи «serpentine» [Even, Pop 1994: 340].

По мнению И. де Рахевильца, Tünggelik/Тенгели входит в ареал местности Бурги Эрки (Bürgi-erki) [The Secret History... 2004: 402]. С. А. Козин определяет значение термина burgi как 'водоворот, стремнины', erki-burki, burki-ergi 'подмытый яр, водоворот’ [1941: 31]. Термин burki, встречающийся в ССМ в составе топонима Burgi-erki, в современном монгольском языке не функционирует [Сундуева 2010: 43]. Возможная локализация этого источника сегодня - долина, расположенная в месте впадения р. Байдлаг в Керулен, которая носит название Түнхэн ам.

Другой небольшой ручей Qimurqa-qoroqan/Кимурха, впадающий в р. Онон с запада, отмечается в ССМ как место, где укрывались люди Темужчина после нападения тайчиудцев. В § 89 Темучжин, освободившись из плена, отправился искать своих людей. Напав на их след в траве, он двинулся вверх по Онону и обнаружил их на холме Хорчухуй (Qorcuqui boldaq) мыса Бедер по берегу речушки Кимурха. 
Как только они воссоединились там, они ушли и обосновались в горах Гурелгу - Gürelgii (вар. Рахевильца)/Kulelku (вар. Козина) - на южном склоне массива Burqan-qaldun/Бурхан-халдун. Среди мест, где они кочевали, упоминается ручей Сэнгур - Senggür (вар. Рахевильца)/ Sankur-qoroqan (вар. Козина).

3. ycyн/usun. Довольно редко в ССМ отмечается гидрографический термин usun, применяемый по отношению к водным источникам наподобие ручьев, рек. Один из вероятных гидрографических объектов под названием Хачир-усун ( $Q a$ cir-usun), расположенный в Ханхайской местности (Qanqai) (расшифрованной Пэрлээ как Хангай), отмеченный в § 193, 195, был идентифицирован как река С. М. Козиным и И. де Рахевильцем [Козин 1941: 146; Rachewiltz 2004: 80]. Локализация этого водного источника, по мнению Пэрлээ, соответствует местности, где протекает речка с названием Хоромсго горхи, расположенной в Хангайском ареале на $47^{\circ}$ с. ш. и $102^{\circ}$ в. д. [1948: 7]. Другой известный исследователь Ван Го Вэй (王國維) ассоциирует Хачир-усун с современной р. Хануй, расположенной между реками Хойто Тамир и Чулуут [Wan Guo Wei 1940: 7]. Однако с результатами фонетического анализа не согласен И. де Рахевильц, считающий, что лагерь Таян-хана находился слишком далеко на западе от Хангайских гор. Он подчеркивает, что сложности в идентификацию местонахождения реки вносит упоминание об Алтайских горах, отмеченных в источниках, использованных Рашид-ад-дином, и приводит мнение Н. Поппе, что под термином «Алтай» могут подразумеваться любые заснеженные горы [The Secret History... 2004: 699]. Таким образом, ясности в определении локализации гидрографического объекта Qacirusun все еще нет.

В этой же версии обозначения водного источника отмечена также речка Soxо

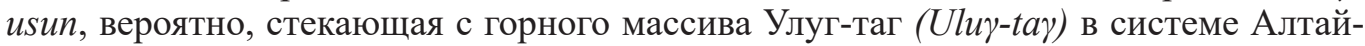
ских гор (§ 158). Полагаем, что термин usun в CСМ в большей степени относился к заболоченным местам. Так, например, в тексте $\S 147$ под выражением čeel usun- $i$ подразумеваются болотистые, тинистые воды [Козин 1941: 240], выражением čegel usun - ключевые воды в $\S 72$, трясины и топи в 209 [Там же: 375]. С. М. Козин в комментариях дает следующие определения: čeel usun - глубокие воды; mo. cegel usun - ключевые воды, низменные места; ceel cegel - мочажина, непросыхающее место [Там же: 544].

4. нуyp/naur. В ССМ упоминается ряд крупных озер, которые без труда идентифицируются с водоемами современной карты региона. Это озера Буир-нуур (Buyӥrnaur) и Kölen-naur (также озеро известно как Далай-нуур в Хулун-Буирском аймаке AРВМ Китая). Одно из них - Kölen-naur сегодня сохраняет два наименования. Обращает внимание название административного аймака Внутренней Монголии, образованного из названий двух его озер - Буир-нуур и Хүлүн-нуур.

5. булаг/bulaq. В тексте ССМ гидрографический термин булаг встречается всего один раз в названии источника Олегай - Olekai-bulaq, что на южном склоне горы Джамала (jalama) (§ 128). В этой местности, расположенной недалеко от степи Саари-кеере, брат Джамухи Тайчар отогнал у Чжочи-Дармалы табун.

6. гол/ $\mathrm{jol} / \mathrm{qol}$

В составе гидронимов средневековой Монголии гол не встречается. Данный термин используется в значении «главный, центральный», например «Великий средний полк».

Ряд водных источников в варианте, переведенном С. М. Козиным, не обозначены гидрографической лексикой: Он ограничивается только упоминанием названия источника. К таким неопределенным, с точки зрения гидрографической классификации, относятся реки Тамир, Халха. 
Таким образом, исследование средневековой гидрографической карты исторического региона, где происходило зарождение Монгольской империи, показывает, что названия значительной части водных источников средневековья легко идентифицируются с существующими в настоящее время гидрографическими объектами. В основном это самые крупные реки региона - Орхон, Селенга, Керулен, Онон, Тола, Оршун, Хилок и озера Буир-нур, Далай-нур. При этом такой крупный и хорошо известный объект, как оз. Байкал, в ССМ не отмечается. С ним, вероятно, связан гидроним Тенгис (Tenkis) в самом начале повествования. В современном этому историческому периоду труде Рашид-ад-дина география региона представлена более подробно и охватывает земли далеко к северу от территорий, описываемых в ССМ. В этих описаниях присутствуют не только озеро Байкал, но и северные реки, в частности р. Ангара (Анкара-мүрэн). Полагаем, что причиной такого невнимания авторов ССМ было выпадение оз. Байкал из границ актуального для формирующегося монгольского общества пространства.

Обозначения небольших рек и ручьев исторического периода, зафиксированного в ССМ, не сохранились. Локализация небольших гидронимов на современной карте все еще не определена, поскольку существующие версии недостаточно обоснованы и дискуссия все еще продолжается. Нестабильность названий малых рек и ручьев связана с тем, что земли вдоль этих водных источников имели меньшее, по сравнению с крупными реками, хозяйственное, стратегическое значение и менее значимое место в географической картине мира. Замещение населения в этих местах в условиях кочевого образа жизни и частых военных конфликтов, эпидемий, дзудов было, очевидно, регулярным явлением в средневековье.

Привлекает внимание преобладание в ССМ гидронимов мүрэн, горхон над булаг, усун и отсутствие распространенного в настоящее время гидронима гол.

Публикачия выполнена при поддержке гранта РФФИ № 19-09-00082 «Внутренняя Азия в исторической картографии, реконструкиия ее историко-культурного прошлого».

\section{Һитература}

Козин С. М. Сокровенное сказание. Монгольская хроника 1240 г. под названием Mongrol-un Niгuča Tobčiyan. Юань Чао Би Ши. Монгольский обыденный сборник. Т. I / С. М. Козин. - М.; Л., 1941. -620 с.

Рашид-ад-дин. Собрание летописей. Т. 1. Кн. 1 / Рашид-ад-дин. - Л.; М.: Изд-во Акад. наук СССР, 1952. - 221 с.

Сравнительно-историческая грамматика тюркских языков. Пратюркский язык-основа. Картина мира пратюркского этноса по данным языка / отв. ред. Э. Р. Тенишев, А. В. Дыбо. - М.: Наука, 2006. - 908 с.

Сундуева E. B. Изобразительная природа гидрографической терминологии в языке «Сокровенного сказания монголов» / Е. В. Сундуева // Научная мысль Кавказа. - 2010. - № 4. C. $42-46$.

Пэрлээ $X$. «Монголын нууц товчоо»-ны газар усны нэрийн тухай урьдчилсан мэдээ / Х. Пэрлээ // Шинжлэх уханб. - 1948. - № 1(16). - Х. 58-75.

Even M.-D. Histoire secrète des Mongols [Mongghol-un ni'uca tobciyan] / M.-D. Even, R. Pop // Chronique mongole du XIII ${ }^{\mathrm{e}}$ siècle. Collection Connaissance de l'Orient ( $\left.{ }^{\circ} 85\right)$, Série mongole, Gallimard Parution. - Paris, $1994-360$ p.

The Secret History of the mongols. Mongolian Epic Chronicle of the Thirteenth Century. Vol. I / trans. with the historical and antr. comm. by I. de Rachewiltz. - Leiden: Brill, 2004.

Pelliot P. Histoire secrète des Mongols: Restitution du texte mongol et traduction française des chapitres 1 à 6 Par Paul Pelliot. Avant-propos par René Grousset. Avertissement par L. Hambis Reliure inconnue. - Paris, 1949. - 199 p. 
王國維. 海寧王靜安先生遺書. - 上海: 商務印書館 - 43種 [Wáng Guó Wéi. Hǎiníng wáng jìng’ān xiānshēng yíshū. - Shànghăi: Shāngwù yìn shūguăn - 43 zhǒng].

\section{References}

Kozin S. M. Sokrovennoe skazanie. Mongol'skaya hronika 1240 g. pod nazvaniem Monggolun Niguča Tobčiyan. Yuan' Chao Bi Shi. Mongol'skij obydennyj sbornik. T. I / S. M. Kozin. - M.; L., 1941. $-620 \mathrm{~s}$.

Rashid-ad-din. Sobranie letopisej. T. 1. Kn. 1 / Rashid-ad-din. - L.; M.: Izd-vo Akad. nauk SSSR, 1952. - $221 \mathrm{~s}$.

Sravnitel'no-istoricheskaya grammatika tyurkskih yazykov. Pratyurkskij yazyk-osnova. Kartina mira pratyurkskogo etnosa po dannym yazyka / otv. red. E. R. Tenishev, A. V. Dybo. - M.: Nauka, 2006. - $908 \mathrm{~s}$.

Sundueva E. V. Izobrazitel'naya priroda gidrograficheskoj terminologii v yazyke «Sokrovennogo skazaniya mongolov» / E. V. Sundueva // Nauchnaya mysl' Kavkaza. - 2010. - № 4. S. 42-46.

Пэрлээ $X$. «Монголын нууц товчоо»-ны газар усны нэрийн тухай урьдчилсан мэдээ / Х. Пэрлээ // Шинжлэх уханб. - 1948. - № 1(16). - Х. 58-75.

Even M.-D. Histoire secrète des Mongols [Mongghol-un ni'uca tobciyan] / M.-D. Even, R. Pop // Chronique mongole du XIII ${ }^{e}$ siècle. Collection Connaissance de l'Orient ( $\left.{ }^{\circ} 85\right)$, Série mongole, Gallimard Parution. - Paris, 1994 - 360 p.

The Secret History of the mongols. Mongolian Epic Chronicle of the Thirteenth Century. Vol. I / trans. with the historical and antr. comm. by I. de Rachewiltz. - Leiden: Brill, 2004.

Pelliot P. Histoire secrète des Mongols: Restitution du texte mongol et traduction française des chapitres 1 à 6 Par Paul Pelliot. Avant-propos par René Grousset. Avertissement par L. Hambis Reliure inconnue. - Paris, 1949. - 199 p.

王國維. 海寧王靜安先生遺書. - 上海: 商務印書館 - 43種 [Wáng Guó Wéi. Hăiníng wáng jìng’ān xiānshēng yíshū. - Shànghăi: Shāngwù yìn shūguăn -43 zhǒng]. 